\title{
Structural and hardness of nonlinear optical L-alanine single crystals
}

\section{S. Gokul Raj ${ }^{1 *}$, G. Ramesh Kumar ${ }^{2}$}

\author{
${ }^{1}$ Department of Physics, Vel Tech Dr. RR \& Dr. SR Technical University, Avadi, Chennai 600062, India \\ ${ }^{2}$ Department of Physics, University College of Engineering Arni, Anna University of Technology Chennai, Arni 632317, India
}

*Corresponding author. E-mail: gokulrajs@yahoo.com

Received: 27 Jan 2011, Revised: 14 May 2011 and Accepted: 01 June 2011

\section{ABSTRACT}

Single crystals of pure and Deuterated L-alanine have been grown by both slow cooling and seed rotation techniques. The grown nonlinear optical crystals were subjected to single crystal X-ray diffraction for determining its lattice parameters and morphology. Thermal expansion measurements were carried for the Deuterated crystals of L-alanine using thermomechanical analyzer in order to ascertain the strain tensors along the three mutually perpendicular crystallographic directions. Microhardness study was also undergone on deuterated L-alanine single crystals on a prominent plane for determining the mechanical strength of the grown crystals. The results have been discussed in detail. Copyright (C) 2011 VBRI press.

Keywords: Characterization; crystal morphology; optical microscopy; recrystallization; organic compounds; nonlinear optical materials.
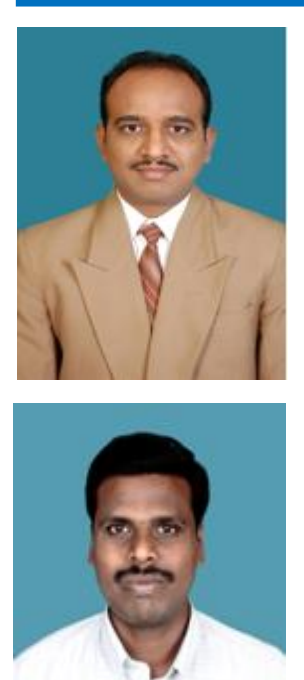

S. Gokulraj is an Associate Professor in the Department of Physics. He was awarded Ph.D in 2006 from Presidency College (Autonomous), Chennai affiliated to University of Madras in the field of Crystal Growth \& Characterization of nonlinear optical materials. His area of specialization encircles around synthesis and characterization of optical, electrical and magnetic materials. He received DST-SERC Young Scientist award in 2008 in the field of Rare earth manganites for Multiferroic applications. He has published 33 research papers in reputed International Journals.

G. Ramesh Kumar is an Assistant Professor of Physics. He received his Ph.D from University of Madras in 2008 (Presidency College (Autonomous), Chennai). His area of research includes optical and ferroelectric materials for device applications for which he was awarded DST-SERC Young Scientist in 2011. Till date he has authored more than 30 International publications.

\section{Introduction}

The group of chiral and ionic organic crystals contains a significant number of materials which have moderately large nonlinearities (1-2 pm/V), favorable phase-matching properties for visible or near ultraviolet region and can grow easily into large with good optical quality.These crystals have gained much importance in recent years [1-3].

Optically active amino acids show high efficient optical second harmonic generation (SHG) and are promising candidates for laser and optical communication technology. Since isomerically pure and optically active substances always meet the symmetry requirements for optical second harmonic generation, there is considerable variation in efficiency for the generation of SHG, ranging from almost zero to greater than that of potassium dihydrogen phosphate crystals. Crystals capable of generating second harmonics must have a unit cell with no centre of inversion and this requirement is met by the crystals of pure amino acids because these molecules themselves are asymmetric [4-6]. Further to that they posses both donor-acceptor molecules having large hyperpolarizabilities which results in the growth of L-alanine, L-histidine, L-arginine and semi-organic compounds like L-arginine phosphate (LAP), L-histidine tetrafluoroborate for second order nonlinear device applications [6-9]. LAP exhibits a significant absorption feature $(1-3 \% / \mathrm{cm})$ in the region between 250 and $300 \mathrm{~nm}$ and is due to the $\pi-\pi^{*}$ transitions. The wavelength of these transitions in carboxylic acids has been 
shown to depend significantly on the molecular structure, but very little information is known about their behaviour in other kinds of organic salts [10-12].

In the near infrared, $(0.9-1.5 \mu \mathrm{m})$ overtone absorptions of $\mathrm{N}-\mathrm{H}, \mathrm{O}-\mathrm{H}$, and $\mathrm{C}-\mathrm{H}$ stretching vibrations can be quite strong. These crystals are extensively hydrogen bonded and consequently have overtone absorptions which lead to losses of $10-20 \% / \mathrm{cm}$ at the $\mathrm{Nd}$ :YAG fundamental wavelength. [13] Deuteration can reduce this absorption significantly. However, deuteration of four covalently bonded C-H stretching is difficult.

Recently we have reported on the growth, deuteration and nucleation studies on L-alanine single crystals $[14,15]$. In the present investigation, good optical quality L-alanine single crystals have been grown from aqueous solution by slow cooling and seed rotation techniques. Deuteration of L-alanine was done using $\mathrm{D}_{2} \mathrm{O}$ as solvent. The morphology of the grown crystals was obtained by single crystal X-ray diffraction analysis. Thermomechanical analyses and microhardness measurements were also carried out for Deuterated L-alanine single crystal.

\section{Experimental}

\section{Crystal growth}

Freshly prepared L-alanine solution was used for the experiment. The polycrystalline powders of L-alanine have been procured from E-Merck with a purity of $99.9 \%$. As per MSD data sheet, the compound is reported to be nontoxic and non-hazardous in nature. Hence the experiment is continued by obtaining small transparent single crystals, free of macro defects, through spontaneous nucleation from the saturated solution of L-alanine. For the bulk growth of the title crystal, mother solution of L-alanine was saturated to $40^{\circ} \mathrm{C}$ and a transparent seed was introduced into the saturated solution placed in a constant temperature bath of accuracy $\pm 0.01^{\circ}$ C.The solution was maintained at the saturated temperature for 24 hours. The solution was then allowed to cool@0.1 $0.1^{\circ} \mathrm{C} /$ day under constant stirring. Transparent crystals with well defined morphology elongated along c-axis of size $20 \mathrm{~mm}$ x $15 \mathrm{~mm}$ x $5 \mathrm{~mm}$ were grown after a typical growth period of 30 days. For the growth of seed rotated L-alanine single crystals, the procedure mentioned elsewhere $[\mathbf{1 6}, \mathbf{1 7}]$ was used. Single crystals of deuterated L-alanine were also prepared by the exchange reaction with heavy water $\left(\mathrm{D}_{2} \mathrm{O}\right)$. The degree of deuteration could be improved by the successive crystallization of salt with deuterated water $\left(\mathrm{D}_{2} \mathrm{O}\right)$.

\section{Characterization of Deuterated L-alanine single crystals}

The unit cell dimensions, the space group and morphology of deuterated and seed rotated pure L-alanine crystals were obtained using a Enraf-Nonius CAD4 single crystal X-ray diffractometer equipped with $\mathrm{CuK} \alpha$ radiation $(\lambda=1.54598$ $\AA)$. Lattice parameters were calculated from 50 reflections. Both the compound crystallizes in orthorhombic system with space group $\mathrm{P} 22_{1} 2_{1} 2_{1} \quad\left(\mathrm{D}_{2}{ }^{4}\right)$. The molecular arrangement of L-alanine in crystalline state is shown in Fig. 1. Powder X-ray diffraction patterns were also recorded for both the pure and deuterated poly crystalline powders of L-alanine using a Rigaku D/max-A diffractometer fitted with $\mathrm{CuK} \alpha$ radiation $(\lambda=1.54598 \AA)$. Themomechanical analysis and Microhardness studies were carried out for the deuterated crystal using Mettler TMA analyser and Vickers hardness tester.

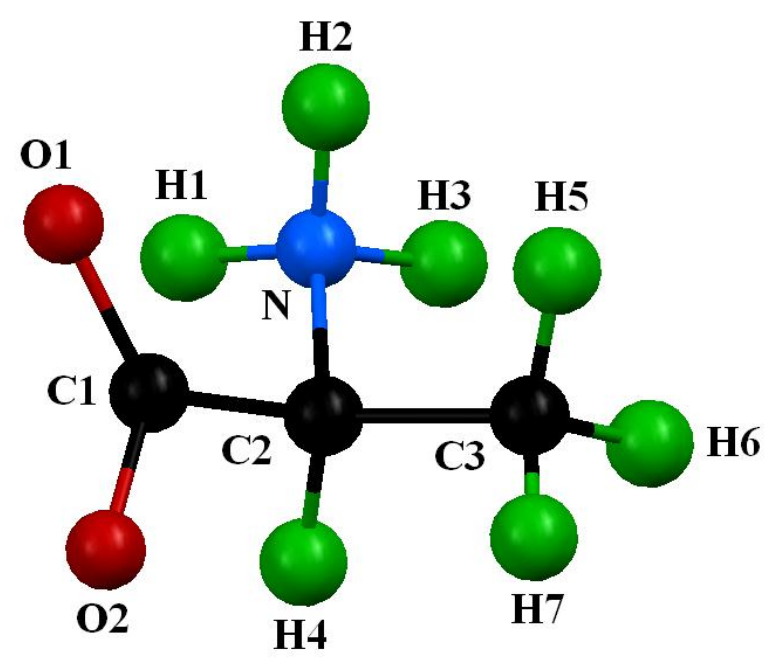

Fig. 1. Molecular arrangement of L-alanine.

\section{Results and discussion}

\section{Single crystal $X$-ray diffraction}

The Morphology of the deuterated L-alanine crystals and crystals grown by seed rotation were measured from a single-crystal diffractometer. The crystal data of L-alanine is presented in Table 1. The crystal parameters and cell volume found to be in well agreement with that of reported values [18]. The morphology of deuterated and seed rotated L-alanine single crystals were shown in Fig. 2 and $\mathbf{3}$, respectively.

Table 1. Crystallographic details of L-alanine.

\begin{tabular}{lcc}
\hline Molecular formula & \multicolumn{2}{c}{ L-alanine $\left(\mathrm{C}_{3} \mathrm{H}_{7} \mathrm{NO}_{2}\right)$} \\
& $\begin{array}{l}\text { Determined from } \\
\text { Single crystal XRD }\end{array}$ & From Literature \\
\hline Unit cell parameters & $\mathrm{a}=6.041 \AA$, & $\mathrm{a}=6.032 \AA$, \\
& $\mathrm{b}=12.353 \AA$ and & $\mathrm{b}=12.343 \AA$ and \\
& $\mathrm{c}=5.774 \AA$ & $\mathrm{c}=5.784 \AA$ \\
Cell volume & $431.12 \AA^{3}$ & $430.09 \AA^{3}$ \\
System & Orthorhombic & Orthorhombic \\
& $\left(\alpha=\beta=\gamma=90^{\circ}\right)$ & $\left(\alpha=\beta=\gamma=90^{\circ}\right)$ \\
space group & $\mathrm{P} 22_{1} 2_{1} 2_{1}\left(\mathrm{D}_{2}{ }^{4}\right)$ & $\mathrm{P} 2_{1} 2_{1} 2_{1}\left(\mathrm{D}_{2}{ }^{4}\right)$ \\
\hline
\end{tabular}

The morphology of the deuterated crystals yielded similar results to that of pure L-alanine crystals $[\mathbf{1 8}, \mathbf{1 9}]$. The length of the crystal is also elongated along the ' $c$ ' direction. The top and the bottom planes of the crystal are Friedel pairs. The unit cell parameters were found to be $\mathrm{a}=$ 
$6.049 \AA, b=12.315 \AA$ and $c=5.823 \AA$. The largest face is always found to be $\left\{\begin{array}{lll}1 & 2 & 0\end{array}\right\}$ and $\left\{\begin{array}{lll}0 & 2 & 0\end{array}\right\}$ is one of the smallest in the case of deuterated L-alanine.

The single crystal X-ray diffraction analysis of seed rotated and deuteterated L--alanine single crystals revealed that the unit cell parameters are almost same as that measured for slow evaporation technique. This reveals that there is no much difference in the structural rearrangement on the crystal grown by seed rotation. The growth of the plane along $\left\{\begin{array}{llll}1 & 2 & 0\end{array}\right\}$ face is slower which was prominent in the crystal grown by slow evaporation techniques.

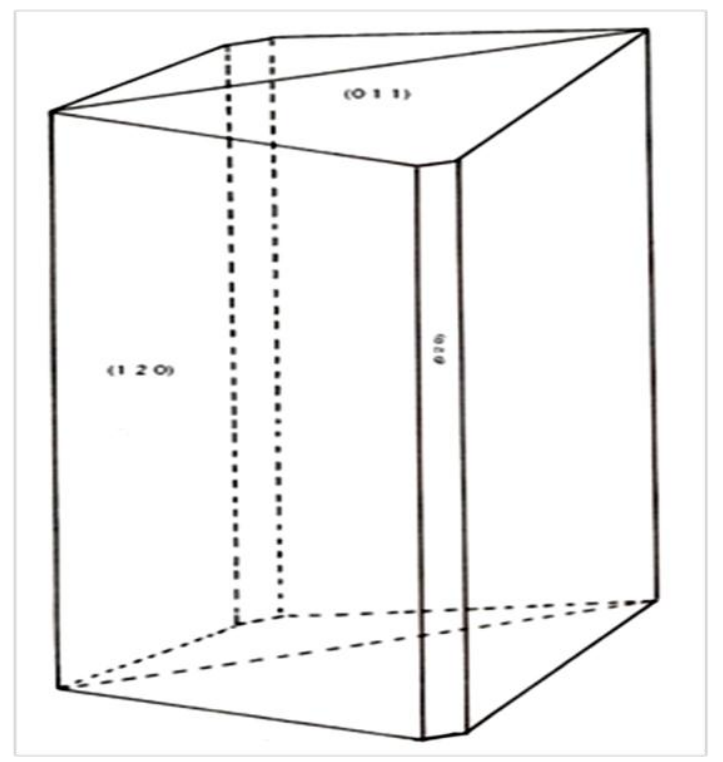

Fig 2. Morphology of L-alanine single crystal.

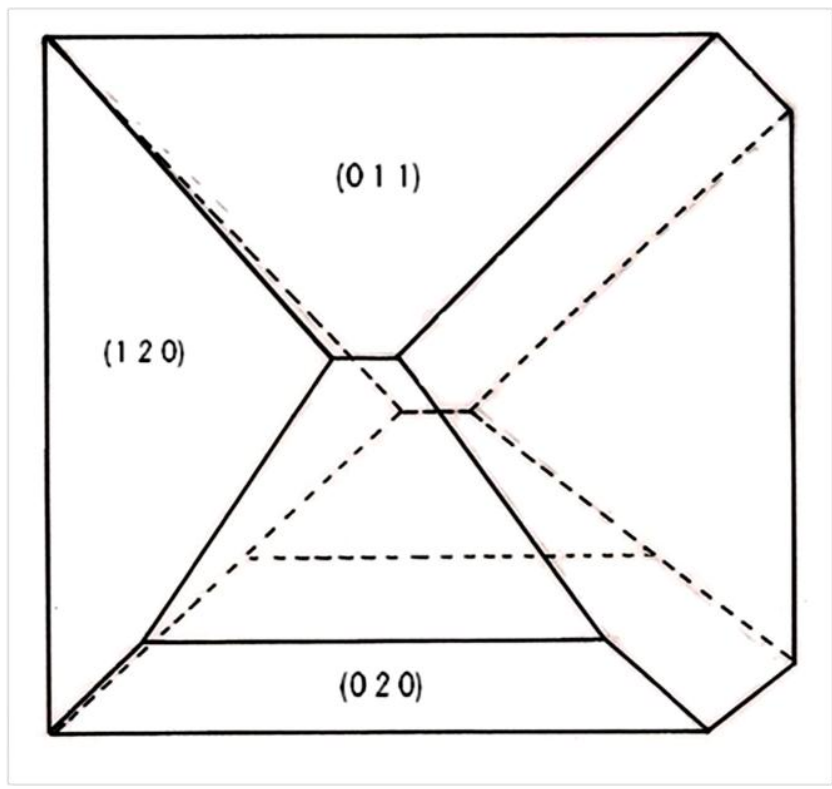

Fig. 3. Morphology of L-alanine crystals grown by seed rotation technique.
Powder X-ray diffracton of pure and deuterated L-alanine single crystals

Powder X-ray diffraction patterns were obtained at room temperature for both the pure and deuterated L-alanine polycrystalline samples. The XRD pattern for pure and deuterated L-alanine is shown in Fig. 4.

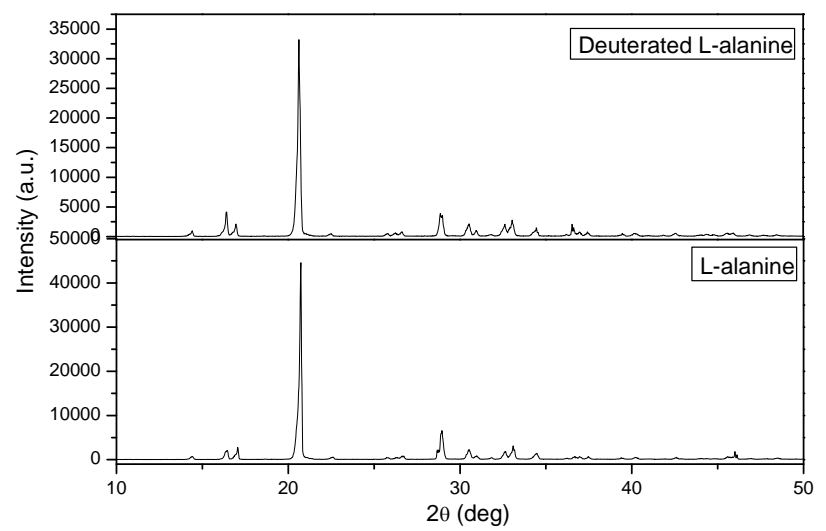

Fig. 4. Powder X-ray diffraction pattern of pure and deuterated L-alanine single crystal.

The lattice parameters were found to be $a=6.04 \AA, b=$ $12.30 \AA$ and $\mathrm{c}=5.80 \AA$ for deuterated L-alanine crystals. This is in close agreement with the values obtained from single crystal X-ray diffraction analysis for L-alanine [19]. Furthermore, the intensities appear in the same diffraction planes indicating that there is no much change in the orientation during the growth of the crystals. This is because, in general, three types of site replacement of deuterium ions can occur while deuteration. They are, (i) $\mathrm{NH}$ can be replaced as ND, (ii) $\mathrm{CH}$ can be replaced as $\mathrm{CD}$ and (iii) both $\mathrm{NH}$ and $\mathrm{CH}$ can be replaced as ND and $\mathrm{CD}$ [20]. It is shown in below in the scheme.

The deuteration of the $\mathrm{CH}$ (III and IV) sites is high when the compound is synthesized through electrolytic reduction [21]. The deuteration of $\mathrm{NH}$ (II) and $\mathrm{OH}$ sites can be easily achieved by recrystallization from aqueous $\mathrm{D}_{2} \mathrm{O}$ solution [18]. The deuteration of the $\mathrm{OH}$ and $\mathrm{NH}$ sites can be brought arbitrarily close to $100 \%$ by successive recrystallization.

\begin{tabular}{|c|l|l|}
\hline $\mathrm{CH}_{3} \mathrm{CH}\left(\mathrm{NH}_{3}\right)^{(+)} \mathrm{CO}_{2}^{(-)}$ & $\mathrm{CH}_{3} \mathrm{CH}\left(\mathrm{ND}_{3}\right)^{(+)} \mathrm{CO}_{2}^{(-)}$ & II \\
\hline $\mathrm{CH}_{3} \mathrm{CD}\left(\mathrm{NH}_{3}\right)^{(+)} \mathrm{CO}_{2}^{(-)}$ & III \\
\hline $\mathrm{CH}_{3} \mathrm{CD}\left(\mathrm{ND}_{3}\right)^{(+)} \mathrm{CO}_{2}^{(-)}$ & $\mathrm{IV}$ \\
\hline
\end{tabular}

Thermomechanical analysis of deuterated L-alanine single crystals Strain and crystal symmetry

The strain of a crystal is not a crystal property, but, rather, a response of a crystal to an external influence. The strain produced by the stress either through elastically or in the form of electric fields need not conform to the symmetry of the crystal unless the strain or the field itself conforms. On the other hand, the strain caused by a change in 
temperature (thermal expansion), conform to the original symmetry of the crystal as per Neumann's principle.

\section{Thermal expansion}

If the temperature of the crystal is changed, the resulting deformation is may be specified by the strain tensor, represented as " $\varepsilon_{i \varphi}$ ". When a small temperature change $\Delta \mathrm{T}$ takes place uniformly throughout the crystal, then the deformation shall be considered as homogeneous, and it is found that all the components of " $\varepsilon_{\mathrm{l} \varphi}$ "are proportional to $\Delta \mathrm{T}$; thus the thermal expansion tensor or strain tensor can be written in the form:

$$
\varepsilon_{1 \varphi}=\alpha_{1 \varphi} \Delta \mathrm{T}
$$

where $\varepsilon_{i \varphi}$ are constants of coefficients of thermal expansion and $\Delta \mathrm{T}$ is the heating rate. In terms of principle axis, the strain tensor can be represented as:

$$
\begin{aligned}
\varepsilon_{1} & =\alpha_{1} \Delta \mathrm{T} \\
\varepsilon_{2} & =\alpha_{2} \Delta \mathrm{T} \\
\varepsilon_{3} & =\alpha_{3} \Delta \mathrm{T}
\end{aligned}
$$

where $\alpha_{1}, \alpha_{2}, \alpha_{3}$ are coefficients of thermal expansion along mutually perpendicular $c, b$ and a axes. If the sphere is drawn in a crystal, it becomes, on change of temperature, an ellipsoid (the strain ellipsoid) with axes proportional to $\left(1+\alpha_{1} \Delta \mathrm{T}\right),\left(1+\alpha_{2} \Delta \mathrm{T}\right),\left(1+\alpha_{3} \Delta \mathrm{T}\right)$. The representation quadric for the thermal expansion has the equation:

$$
\alpha_{1 \times 1}{ }^{2}+\alpha_{2 \times 2}{ }^{2}+\alpha_{3 \times 3}{ }^{2}=1
$$

The shape and orientation of the quadric is subject to the restrictions imposed by the symmetry of the crystal. Its different forms, the rigorous theory behind the strain and thermal expansion relations for various crystal systems and its theory aspects has been described elaborately elsewhere [22].

Based on the above fundamentals, the thermo mechanical analysis (TMA) was carried out for deuterated L-alanine single crystals in the temperature range $50-130^{\circ}$ $\mathrm{C}$ at a heating rate of $5^{\circ} \mathrm{C} / \mathrm{min}$ in air atmosphere. Since the title compound crystallizes in an orthorhombic system, the principal expansion coefficient tensor coincides with the crystallographic axes [22] and the lengths $1_{1}=4.12 \mathrm{~mm}, 1_{2}=$ $2.55 \mathrm{~mm}, \mathrm{l}_{3}=2.68 \mathrm{~mm}$ have been regarded as $\mathrm{c}, \mathrm{b}$ and aaxes of the crystal respectively.

So, equation of the strain ellipsoid is given by

The representation quadric for thermal expansion of the grown crystal has been projected along a-axis and it is shown in Fig. 5. The thermal expansion coefficient along the three axes of deutereted L-alanine single crystal is shown in Fig. 6. The mean thermal expansion tensor $\alpha_{i \varphi}$ of deuterated L-alanine crystal from Fig. 6 is given by:

$\alpha=\left(\begin{array}{lll}3.98 & 0 & 0 \\ 0 & 3.084 & 0 \\ 0 & 0 & 1.938\end{array}\right) \times 10^{-5} /{ }^{\circ} \mathrm{C}$ which correspond to $\mathrm{c}, \mathrm{b}$ and a-axes;

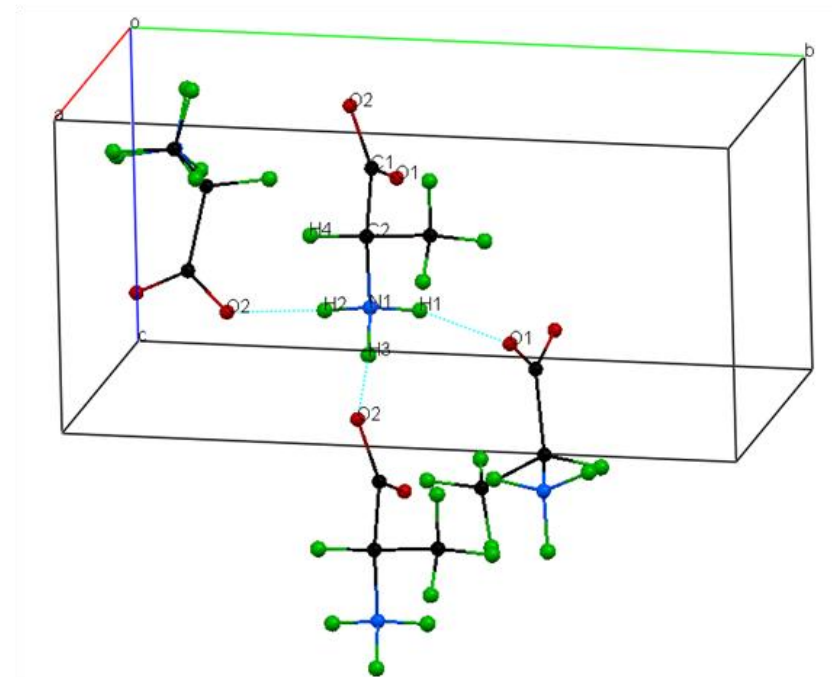

Fig. 5. Thermal expansion projection of L-alanine along a-axis.

From the above Fig. it was found that no negative thermal expansion has been observed in deuterated Lalanine single crystal in all mutually perpendicular crystallographic axes. The coefficients of thermal expansions are comparable to that of L-alanine single crystal [18]. Deuterated L-alanine crystal also shows large expansion coefficient along c-axis when compared to $\mathrm{b}$ and a-axes.

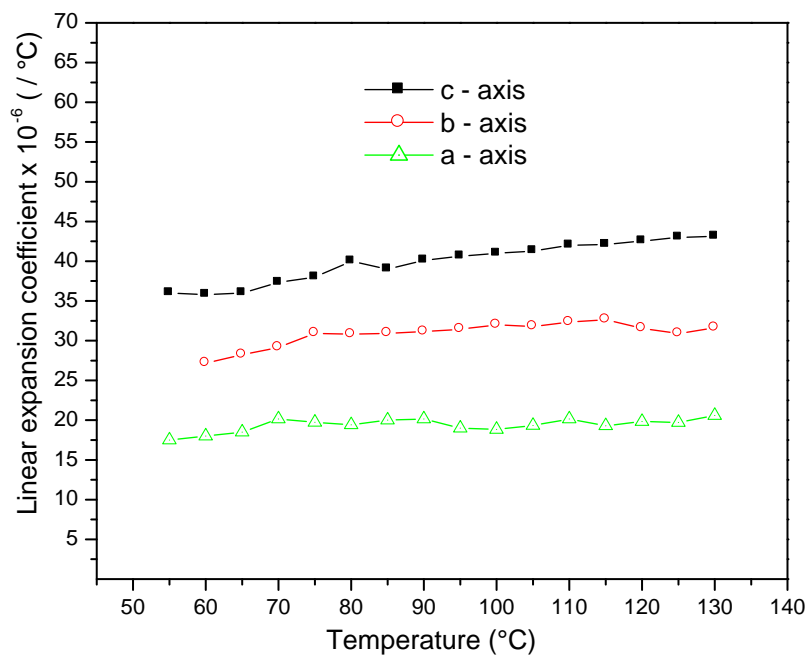

Fig. 6. Anisotropy of linear expansion coefficient along the three axis for deuterated L-alanine single crystals.

Deuterated L-alanine is stabilized by N-H...O type and $\mathrm{O}-\mathrm{H}$... O type hydrogen bonds. The crystallographic $\mathrm{b}$ and c axes are linked through a chain of $\mathrm{N}-\mathrm{H}$... O bonds while a-axis linked by a chain of $\mathrm{O}-\mathrm{H}$... O bonds. The higher expansion coefficient along c-axis can be attributed to longer intramolecular contact and hence the bond is weak in nature when compared to O-H...O bond.

The expansion coefficient of Deuterated L-alanine was found to be $4.064 \times 10^{-5} /{ }^{\circ} \mathrm{C} \quad$ and is comparable with similar amino acid L-threonine [23]. This probably makes the crystal feasibility to be useful in electro optic Pockel's 
devices. This behaviour will be more important when one considers manufacturing devices such as waveguide and interferometer with deuterated L-alanine single crystals.

\section{Microhardness measurements}

Hardness is an important solid state property and plays a vital role in device fabrication and hence Vicker's microhardness measurement was carried out for L-alanine crystals to assess its mechanical strength. To evaluate the vicker's hardness number, as grown crystals of L-alanine were subjected to static indentation test at room temperature using Shimadzu HMV2 hardness tester fitted with vicker's diamond pyramidal indentor. Several indentations were made on the $\left(\begin{array}{lll}1 & 2 & 0\end{array}\right)$ face along the $\left(\begin{array}{lll}0 & 0 & 1\end{array}\right)$ of L-alanine crystal. The vicker's hardness number was calculated using the expression:

$$
\mathrm{H}_{\mathrm{v}}=1.8544\left(\mathrm{P} / \mathrm{d}^{2}\right)
$$

where $H_{v}$ is the vicker's hardress number for a given load, $P$ in gram and ' $\mathrm{d}$ ' is the average diagonal length of the indentation in $\mathrm{mm}$. At lower loads there is an increase in the hardness number which can be attributed to the electrostatic attraction between the zwitterions present in the molecule.

The surface pattern of the as grown and lapped crystals is shown in Fig.7 (a) and 7(b). In Fig.7 (b), the focus of the eyepiece does not coincide with the surface and since there is a difference in height between adjacent places. Hence care should be taken to avoid the irregularity in the surface lattice while making indentations.
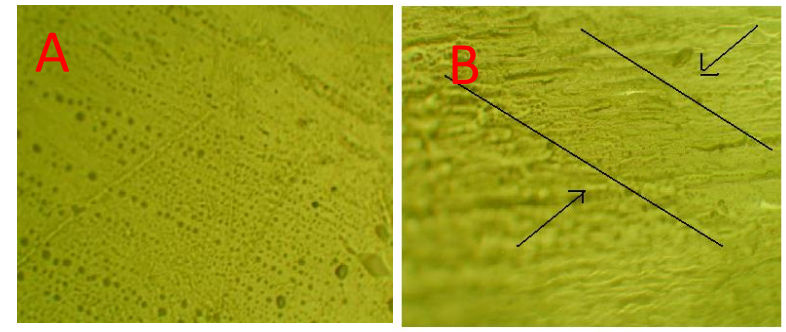

Fig. 7. (a) and (b) Surface pattern of as grown and lapped crystals of Lalanine.

The indentation for the lapped crystals of dimensions 5 $\mathrm{mm} \times 5 \mathrm{~mm} \times 2 \mathrm{~mm}$ along $\left\{\begin{array}{lll}0 & 2 & 0\end{array}\right\}$ plane is shown in Fig.8. For the loads of 10 gram and 25 gram cracks are formed on the surface. The indentation was done along the $\left.\begin{array}{llll}0 & 2 & 0\end{array}\right\}$ plane for which the hardness number was found to be 48 and 52 for the loads of 10 gram and 25 gram respectively. From the figure it is clear that even for load of 10 gram, crack appears. This represents the low hardness along this particular direction.

Fig. 9 shows indention mark taken along the largest plane $\left\{\begin{array}{lll}1 & 2 & 0\end{array}\right\}$ for which the crystal possess high hardness number. For loads of 10, 25, 50 and 100 gram the hardness number was found to be 79.3, 86.1, 70.7 and 71.9. Cracks were formed when the load is increased to 200 gram. It is clear from the figure that for the red circle which corresponds to $200 \mathrm{~g}$ load the crack widens. The red arrow marks shown in the figure represents the crack extending on one side along $\left\{\begin{array}{llll}0 & 2 & 0\end{array}\right\}$ for which the thermal stability was very low as explained earlier.

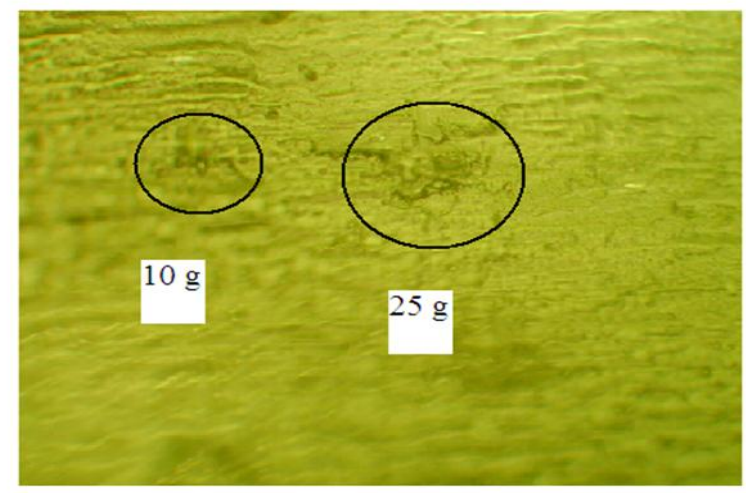

Fig. 8. Surface indentation pattern for loads 10 and 25 grams for $\left\{\begin{array}{lll}0 & 2 & 0\end{array}\right\}$ plane.

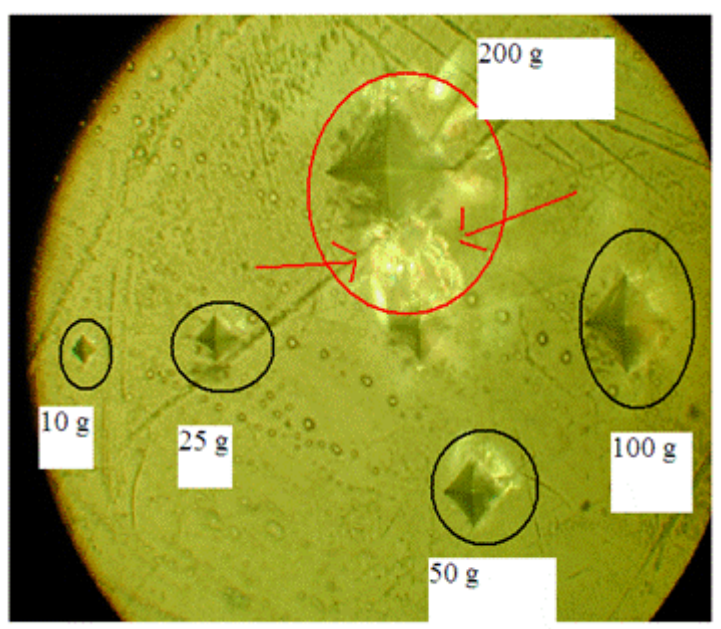

Fig. 9. Surface indentaion pattern for all measured loads along $\left\{\begin{array}{lll}1 & 2 & 0\end{array}\right\}$ plane.

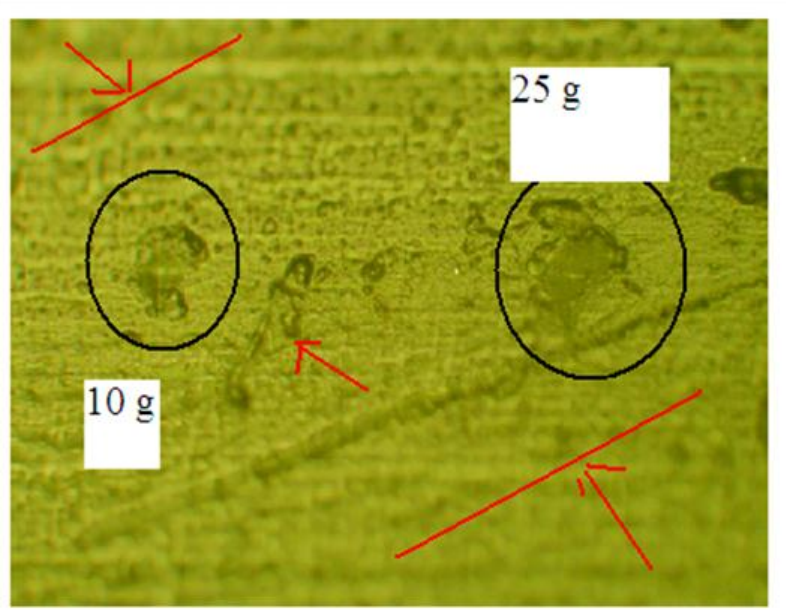

Fig. 10. Surface pattern of indented area for 10 and 25 grams load. 
Fig. 10 shows the surface pattern of as grown and lapped crystals of deuterated L-alanine. The hardness number was found to be 25 and 30 for loads of 10 and 25 gram cracks begins to appear along the $\left\{\begin{array}{lll}0 & 2 & 0\end{array}\right\}$ plane as it was weak plane as shown in pure $\mathrm{L}$-alanine also. The black circles represent the indention area. It is clear from the figure that the crystal begins to crack even for minimum load. The red arrow represents the uneven crystal surface formed during lapping. At higher loads, the hardness shows a sharp decrease and beyond $50 \mathrm{gm}$ significant crack occurs.

\section{Conclusion}

Deuterated and pure L-alanine crystals have been grown by both slow cooling and seed rotation techniques for the first time.

1. From single crystal and powder XRD measurements, it was found that both the deuterated and pure L-alanine single crystals have iso-structural unit cells.Deuteration has not altered the crystallographic properties of the grown crystals.

2. Morphology of crystals grown from both slow cooling and seed rotation techniques yielded with the same miller planes. No additional face was observed for the deuterated one. (020) plane was found to be the best and smallest plane with good optical quality. This result resembles with pure L-alanine.

3. Thermal Expansion measurement reveals that deuterated L-alanine possess lower thermal expansion coefficient values along the three crystallographic axes and they are in the order of few tens of microns per centigrade rise in temperature. For waveguide and other NLO device applications, samples should be usually of size $1 \mathrm{~cm} \mathrm{x} 1 \mathrm{~cm}$. It infers that, even due to laser heating, the title crystal would be experiencing only an expansion of the aforesaid order of micron which is far lower, when compared with the actual dimension of the samples under usage.

4. Hardness measurements on the Deuterated L-alanine on various planes reveal that the crystal is mechanically stable upto 200gram of the applied load. This indicates that the material having appreciable hardness values shall withstand higher laser damage threshold values which may be useful for the high frequency conversion devices.

\section{Acknowledgements}

One of the authors Dr. S. Gokul Raj wishes to thank the founder and chairman Prof. Dr. R. Rangarajan, and all the Management members of Vel Tech Dr. RR \& Dr. SR Technical University, Avadi, and Chennai for providing a platform to perform the research and Dr. G. Ramesh Kumar wish to thank the Hon'ble Vice-chancellor, the Registrar and the Director for research, Anna university of Technology, Chennai for their constant encouragement and support extended to carry out this work.

\section{Reference}

1. Marder, S.R.; Perry, J.W., Yakymyshyn, C.P. Chem. Mater. 1994, 6, 1137.

DOI: $10.1021 / \mathrm{cm} 00044 \mathrm{a} 012$

2. Chemla, D.S.; Zyss, J. Nonlinear Optical Properties of Organic Molecules and Crystals, Academic Press, NewYork, 1987.

3. Hann, R.A.; Bloor, D. (eds) Organic materials for nonlinear optics, Royal Society of Chemistry Special Publications, London: RSC, 1989.
4. Frazier, C.C.; Cockerhamn, M.P.; Chauchard, E.A.; Lee, C.H. J. Opt Soc. Am. 1987, 4, 1899. DOI: $10.1364 / \mathrm{JOSAB} .4 .001899$

5. Gunter, P.; Bosshard, Ch.; Sutter, K.; Arend, H.; Chapuis, G.; Twieg, R.J.; Dobrowolski, D. Appl. Phys. Lett. 1987, 50, 486. DOI: $\underline{10.1063 / 1.98181}$

6. Eimerl, D.; Velsko, S.; Davis, L.; Wang, F.; Loiacoo, G.; Dennedt, G. IEEE J. Quantum Electron. 1989, QE 25, 179. DOI: $10.1109 / 3.16261$

7. Monaco, S.B.; Davis, L.E.; Velsko, S.P.; Wong, F.T.; Eimerl, D. J. Cryst. Growth. 1987, 85, 252.

DOI: $\underline{10.1016 / 0022-0248(87) 90231-4}$

8. Marcy, H.O.; Rosker, M.J.; Warren, L.F.; Cunningham, P.H.; Thomas, C.A.; Deloach, L.A.; Velsko, S.P.; Ebbers, L.A.; Liao, J.H.; Kanatzidis, M.G. Opt. Lett. 1995, 20, 252.

DOI: $10.1364 /$ OL.20.000252

9. Aggarwal, M.D.; Choi, J.; Wang, W.S.; Bhat, K.; Lal, R.B.; Shields, A.D.; Penn, B.G.; Frazier, D.O. J. Cryst. Growth. 1999, 204, 179. DOI: $10.1016 / \mathrm{S} 0022-0248(99) 00200-6$

10. Szyper, M.; Zuman, P. Anal. Chim. Acta. 1976, 85, 357. DOI: $10.1016 / \mathrm{S} 0003-2670(01) 84702-4$

11. Krishnakumar, V.;, Rajaboopathi, M.; Nagalakshmi, R. Adv. Mater. Lett. Article in Press. DOI: $10.5185 /$ amlett. 2010.12220

12. Goyal, R.K.; Damkale, S.R.; Mulik, U.P.; Negi, Y.S.; Dadge, J. W.; Aiyer, R.C. Adv. Mat. Lett. 2010, 1(3), 264. DOI: $10.5185 /$ amlett.2010.8150

13. Velsko, S.; Eimerl, D. Proc. SPIE 1986, 622, 171

14. Raghavalu, T.; Ramesh Kumar, G.; Gokul Raj, S.; Mathivanan, V.; Mohan, R.; J. Cryst. Growth. 2007, 307, 112.

DOI: $10.1016 / \mathrm{j}$.jcrysgro.2007.05.053

15. Suriya Kumar, K.; Raghavalu, T.; Mathivanan, V.; Kovendhan, M.; Sivakumar, B.; Ramesh Kumar, G.; Gokul Raj, S.; Mohan, R. J. Cryst. Growth. 2008, 310, 1182.

DOI: $10.1016 /$ j.jcrysgro.2007.12.049

16. Karnal, A.K.; Saxena, A.; Bhat, H.L.; Wadhawan, V.K.; Nathan, T.P.S. J. Cryst. Growth 2006, 289, 617. DOI: $10.1016 /$ j.jcrysgro.2005.11.101

17. Karnal, A.K.; Saxena, A.; Ganesamoorthy, S.; Indranil Bhaumik.; Wadhawan, V.K.; Bhat, H.L.; Gupta, P.K. J. Cryst. Growth, 2006 297, 152.

DOI: $10.1016 / j . j$ crysgro.2006.09.045

18. Misoguti, L.; Varela, A.T.; Nunes, F.D.; Bagnato, V.S.; Melo, F.E.A.; Mendes, F.J.; Zilio, S.C. Opt. Mat. 1996, 6, 147.

DOI: $10.1016 / 0925-3467(96) 00032-8$

19. Razzetti, C.; Ardoino, M.; Zanotti, L.; Zha, M.; Paorici, C. Cryst. Res. Technol. 2002, 456.

DOI: $10.1002 / 1521-4079(200205) 37: 5<456:: A I D-$ CRAT456>3.0.CO;2-M

20. Krishnan, R. S.; Sankaranarayanan, K.; Krishnan, K. J. Indian Inst. Sci., 1973, 55(2), 66. DOI: journal.library.iisc.ernet.in/archives/v55-2.htm

21. Suzuki, S.; Ohshima, T.; Tamiya, T.; Fukushima, K. Shimanouchi, T.; Mizushim, S.I. Spectrochim.Acta. 1959, 15, 969 DOI: $10.1016 / \mathrm{S} 0371-1951(59) 80396-9$

22. Nye, J. F, Physical Properties of Crystals, Oxford Clarendon Press, 1957, pp. 106.

23. Ramesh Kumar, G.; Gokul Raj, S.; Bogle, K.A.; Dhole, S.D.; Bhoraskar, V.N.; Mohan, R. Appl. Surf. Sci. 2008, 254, 5231. DOI: $\underline{10.1016 / \mathrm{j} . \text { apsusc. } 2008.02 .030}$ 


\section{AdVANCEd MATERIALS Letters}

\section{Publish your article in this journal}

ADVANCED MATERIALS Letters is an international journal published quarterly. The journal is intended to provide top-quality peer-reviewed research papers in the fascinating field of materials science particularly in the area of structure, synthesis and processing, characterization, advanced-state properties, and applications of materials. All articles are indexed on various databases including $\underline{D A}$ J and are available for download for free. The manuscript management system is completely electronic and has fast and fair peer-review process. The journal includes review articles, research articles, notes, letter to editor and short communications. 